\title{
Reference Model for Academic Results Certification in Student Mobility Scenarios
}

\author{
Sérgio Cardoso ${ }^{1 *}$, Henrique Mamede ${ }^{2}$, Vitor Santos ${ }^{3}$
}

\author{
${ }^{1}$ Escola Superior Gestão e Tecnologia, IPSantarém, Santarém, PORTUGAL \\ ${ }^{2}$ INESC TEC, Universidade Aberta, Lisboa, PORTUGAL \\ ${ }^{3}$ NOVA IMS - Universidade Nova de Lisboa, Lisboa, PORTUGAL \\ *Corresponding Author: sergio.cardoso@esg.ipsantarem.pt
}

Citation: Cardoso, S., Mamede, H. S. and Santos, V. (2020). Reference Model for Academic Results Certification in Student Mobility Scenarios. Journal of Information Systems Engineering and Management, 5(4), em0125. https://doi.org/10.29333/jisem/8491

\begin{tabular}{|c|c|}
\hline ARTICLE INFO & ABSTRACT \\
\hline Published: 30 Aug. 2020 & $\begin{array}{l}\text { The exchange of academic results between HEIs (Higher Education Institutions) is mandatory in every student } \\
\text { mobility program (i.e. the EU Erasmus Program) but that process remains to present date with insufficient } \\
\text { technological support and the absence of a comprehensive reference model that allows the integration of } \\
\text { potential technological solutions for the exchange of academic data with existing Academic Information Systems } \\
\text { seems to limit greatly the possibility of adopting solutions of this type referred to in the existing literature. This } \\
\text { work addresses this problem, conducting an initial bibliographic review aimed at the identification of the } \\
\text { fundamental requirements of such an architecture as well as explores some of the technologies that are showing } \\
\text { potential for usage in the safe exchange of academic results between partner HEls, with particular interest in } \\
\text { blockchain technology applied in an educational context. }\end{array}$ \\
\hline
\end{tabular}

Keywords: higher education, Erasmus mobility, results certification, educational blockchain

\section{INTRODUCTION}

Each Erasmus mobility involves the exchange of academic records obtained by the student between member HEls (Higher Education Institutions). It is often the case that the transnational communication takes place by reference to the Erasmus coordinator institutional role in a given $\mathrm{HEI}$, supported by the delivery of well-established documentation models such as "learning agreement" and "transcript of records". In (Pelaitis \& Spathoulas, 2018) we find the fundamental reasons that justify the need for "information exchange" between the different HEls, together with the functional description of the mobility program itself.

However, the vast majority of HEls use their own alS (Academic Information Systems), their own databases and some proprietary formats (Turkanovic et al., 2018) for the long term preservation of the records concerning the certification of academic results obtained by the students - for all of them, not only the exchange programs students. A scenario where better interoperability between the alS exists in the HEls is therefore desirable since the alS in use are profoundly diverse (both in technological approaches as in functional aspects) and were specifically built in response to the respective national regulatory frameworks, therefore offering an imperfect response in face of mobility programs such as Erasmus.

The use of BCT technology (BCT - blockchain technology) for the certification of academic results has been advised by several authors and has received growing manifestations of interest. In Kamišalić et al. (2019), some advantages are identified as (1) the bureaucratic facilitation of the internationalization processes for mobility programs or in the management of joint-degree programs as well as (2) in the reinforcement of efficiency levels in the administrative services and therefore the reduction of the budgetary/financial needs for running such programs.

In Kamišalić et al. (2019), we have seen some returns on using BCT for this purpose, considering that the technology is compatible with some principles commonly observed in the academic world, such as the "authenticity of documents, transparency, immutability and trust", which are broadly seen as requirements for the certification of academic results.

It is already possible to identify some initiatives mostly pointed for improving the digital response necessary in students' academic mobilities, centered on the recognition and on transferring the ECTS credits obtained, however, the lack of a clear, normative framework, compatible with formal and regulatory requirements remains to be implemented. Turkanovic et al. (2018) discuss the need to "adopt and implement a global, decentralized, safe and reliable platform" for long term preservation and certification of academic results. 
The mobility scenario in an Erasmus context only emphasizes the need to produce better answers to these questions in order to fulfill formal obligations on information exchange between HEls representing each one of the mobilities successfully carried out by the students.

This paper is organized in sections as follows: the first section introduces the problem and also highlights the contribution and motivation for this work. The second section describes significant related work and after we offer the preliminary view for the model outline. Finally, the ongoing and future work is mentioned followed by the alphabetical list of all the references used.

\section{Contribution}

This position paper introduces the work in progress to build such a reference model for issuing and exchanging (between HEIs) certified academic records obtained in Erasmus mobility scenarios, including the design and implementation of a functional prototype for further evaluation and to demonstrate the global properties of the solution by integrating with one specific alS.

The research methodology to be used is DSR (Design Science Research) (Peffers et al., 2007) with recurring cycles of design, demonstration and evaluation in order to improve the usefulness of the artifacts in close regard of the identified problem.

\section{Motivation}

The information that certifies a certain specific academic path is maintained indefinitely by the HEls (i.e. for a period determined by legal and regulatory dimensions typically defined on a national scale), under different standards and technological platforms (Turkanovic et al., 2018), and the full access to the records being often challenging to ensure between different entities involved (different HEls, employers, supervisory entities, among others).

For BCT technology to be applied in the certification of academic results there is a need to produce well defined standards (Williams, 2019) to be used and broadly accepted, which is why there are currently numerous initiatives and projects in this area. Authors such as Grech and Camilleri (2017) have identified the following potential uses of this technology in an educational usage especially suited for the European Union (EU) context in:

- Accreditation systems;

- Credit recognition and transfer systems;

- Control and reward systems for the use of intellectual property;

- Student financing and payment systems.

Taking into account the existence of initiatives considered to be priorities within the EU and in the EU member states, as for the imminent availability of an EBSI (European Blockchain Services Infrastructure) (Lions et al., 2018), this seems to open an opportunity for addressing the problem associated with the exchange of academic results obtained in the EU territory - mainly because there is a strong regulatory framework defined on a supranational scale around the Erasmus program. Our starting point is the need for design and implementation of one model in such a way that produces enough evidence regarding the role of the technology needed for the secure exchange of those academic results along with the integration models concerning the integration with existing alS.

\section{RELATED WORK}

BCT technology is seen as a safe way to exchange and maintain information on a large scale to demonstrate a succession of transactions, without the need to introduce central coordination mechanisms (Williams, 2019), all chronologically ordered that have occurred in a perfectly determined context.

In addition to information storage uses, BCT technology allows the use of contracts (smart contracts) to define how certain rules are to be applied to govern the way resources are transferred between participating entities (Pelaitis \& Spathoulas, 2018). In short: they symbolize a set of applicable rules as well as how to process the respective resources. This feature allows safe, traceable and irreversible transactions to be carried out, in addition to the fact that the application of pre-determined rules is done without the need for mediation or any central node coordination.

This technological approach has several benefits such as (1) the persistence of student records and their academic certification, (2) the enhancement of the academic certification system reliability, (3) the integrity of the academic records themselves, and finally (4) the decentralized, collaborative and interdependent infrastructure - absolutely compatible with the architecture of the higher education systems in the EU scale. Yet the benefits of enhanced transparency and verification simplicity (even by interested third-parties) are usually highlighted in close association with academic results certification objectives.

Authors like Chen et al. (2018) also conclude over the existence of advantages such as (1) reliability, (2) decentralized trust, (3) security and (4) efficiency, regarding the use of BCT in an educational context - for the purposes previously described.

Examples on BCT technology application in HEls, mainly European ones, can be seen in further detail in Jirgensons and Kapenieks (2018) and the initiatives are typically related to the creation of permanent records on citizens learning paths along with the certification of documents and other academic titles, as well as the certification of acquired knowledge and skills, usually by cross-referencing to the EQF system (European Qualifications Framework System).

In 2018, MIT / media lab presented the solution blockcerts (Jirgensons and Kapenieks, 2018) as an effort to define an openstandard for the future development of applications in this area, aiming to provide a reference for future academic certification works and in fact gave way to numerous initiatives. 


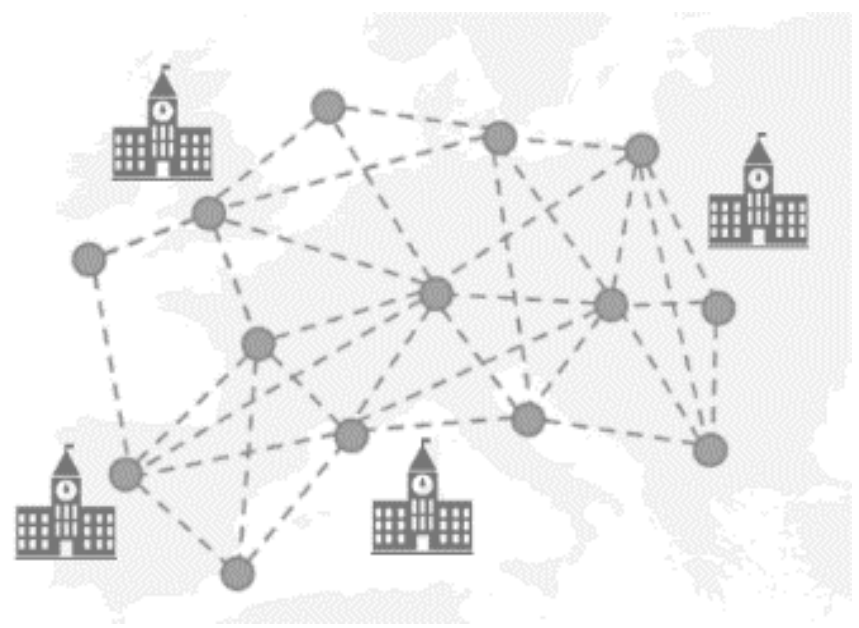

Figure 1. BCT network

There are also projects centered on the ECTS concept (European Credit Transfer and Accumulation System) such as EduCTX (Turkanovic et al., 2018), especially designed to build a platform using the open-source Ark-blockchain based on a distributed model and an interoperable representation of the ECTS obtained by the students. In the work of (Kamišalić et al., 2019) is argued that BCT technology based solutions are not supposed to substitute existing alS, "since there is no benefit of data replication, while additionally having to comply with privacy concerns", which seems a better approach on addressing the coexistence of both systems than the one actually implemented on the EduCTX platform.

The EduCTX project introduces the notion of currency (being an internal crypto currency with no monetary value) as a way to enable transactions via a blockchain wallet (i.e. as existing ECTX tokens). In essence, a student's academic path is represented by the currency amount accumulated on a student's blockchain wallet and each academic achievement adds up a new certain amount of "monetary" units (Turkanovic et al., 2018). However "the EduCTX platform does not provide connectivity with identity management systems" (Kamišalić et al., 2019) to support obtaining a student's identity, with is a arguable option that our work strongly opposes considering the ongoing European Student Card Initiative (CNOUS, 2017).

Other debate should be held around the scale of the models and that introduces specific challenges around the technology to be found most appropriate. Currently we have some $4000 \mathrm{HEls}$ in Europe, around 10 million students (270,000 of them in Erasmus programs). Imagine storing all academic results for all the students enrolled in all academic programs, and doing that once each semester or when students finalize their grades.

Authors as Xu et al. (2017) argue that "the amount of computational power and data storage space available on a blockchain network remains limited.", and therefore our view is only to use BCT technologies for well-defined contexts where academic information exchange is mandatory - such as seen in the Erasmus mobility program and not to replace existing alS. This is a distinctive approach considering the established EduCTX system and other similar initiatives.

Other systems like OpenBlockChain/ KMI (KMI - Open University Knowledge Media Institute) introduce the notion of microcredentialing (Jirgensons and Kapenieks, 2018) (i.e. badges) that represent the student's learning path not designed so much to enhance de formal academic certification but rather to show what topics have one learned. This system is more oriented towards micro-credentialing functions in the certification of life-long learning addressing skills and achievements (common in MOOC / LMS contexts). The underlying idea is for an employer to know what skills I have after a formal and informal training path.

Naturally, all of these systems are built in such a way that the units transferred to a particular student cannot be transferred to a third party. Finally, there are other similar initiatives in progress which we choose not to describe here at this time due to space limitations, but which are easily identified in the bibliographic references used for this work.

\section{MODEL OUTLINE}

The work seen in Xu et al. (2019) describes the BCT technology usage in software architecture models. The discussion takes place around the use of BCT technology predominantly oriented towards (1) information storage (i.e. data storage), (2) the implementation of computing services or (3) for the implementation of communication services. For the implementation of the desired model, it is necessary to create an infrastructure that implements BCT communication services with participating nodes, in which HEls should represent the nodes and where users are naturally students and other academic staff, in terms similar to the work observed in (Turkanovic et al., 2018).

Authors such as Pelaitis and Spathoulas (2018), Turkanovic et al. (2018), Turcu et al. (2018) argue the existence of such an infrastructure for information exchange between different HEls, based on existing HEls mutual responsibilization notions regarding academic records type and form and the desired decentralized management of the model, in a clear contrast to existing conventional solutions hosted by a third entity. The concept is illustrated in Figure 1.

In Xu et al. (2019), there is also a discussion on the need for projects to make a fundamental decision regarding the architectural elements intended for storage and computing functions "that should be placed on-chain and off-chain". The interaction between 


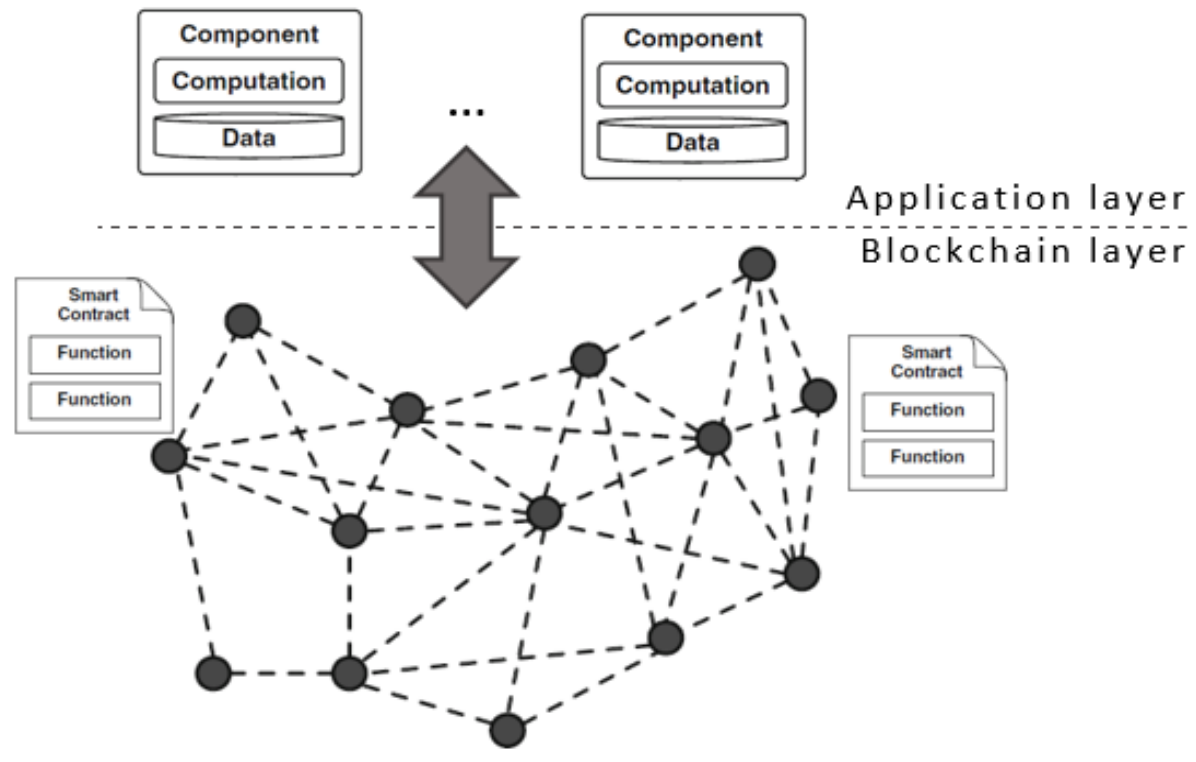

Figure 2. Interaction between applications and BCT

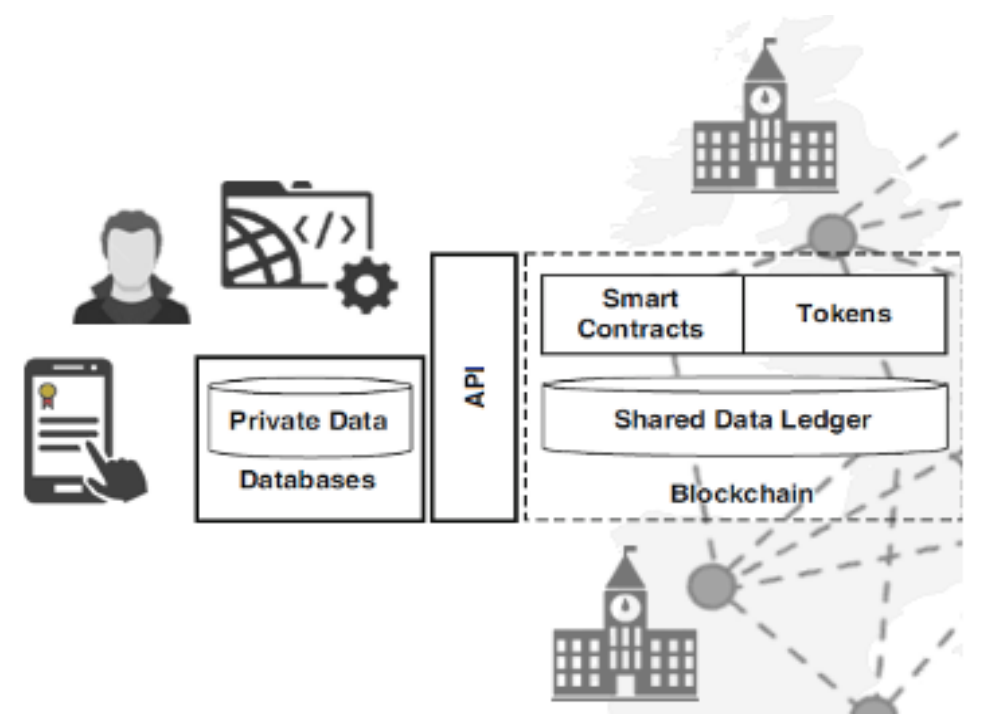

Figure 3. Intended integration with existing information systems

existing applications and BCT technology is to be organized in layers, in close reference to the model seen in (Xu et al., 2019), as shown in Figure 2 (adapted).

Authors as Xu et al. (2017), underline the need to first begin by identifying specific properties to be displayed on the systems as a way to define the most appropriate answers to fundamental questions such as "what type of blockchain?", "which consensus protocol?", "which block size?" or "how often content is introduced into the network?".

On our specific model the need for further work is acknowledged regarding this same fundamental questions, in order to better validate future decisions on what information should be kept on and off chain, as well as what functional elements should be implemented with BCT technology among others equally relevant and therefore more suited for specific uses.

The interaction between both the student and the HEl academic staff with this solution will occur through the use of mobile and web based applications and through other components specifically designed to fulfill integration purposes, such as the work seen in Turkanovic et al. (2018), considering the existing functional and technological diversity of currently existing alS. Figure 3 shows the conceptual representation of the intended integration with existing information systems in HEls.

From a functional perspective, in the anticipated use of BCT technology, it is not intended that the participant nodes perform significant computing operations associated with mining transactions in order to minimize the computational effort required to each participating node and thereby to avoid any impact on the existing technological infrastructure of HEIs. This approach is also seen in Turkanovic et al. (2018) and is argued on the same grounds.

Finally, the exchange of academic results between different HEls, for the context of an designated Erasmus mobility, implies the creation of a student personalized blockchain wallet of non-transferable content and therefore requires the use of a student identity in such a way similar to the one seen in the European Student Card Initiative (CNOUS, 2017), which is currently moving towards an widespread implementation in the European higher education space. 
The unique identity of the student, thus realized, associated with the blockchain wallet where tokens and all other necessary information is to be written, will allow the creation and view of the records associated with the Erasmus mobility carried out, thus making the exchange of academic information between HEls effective without any third-parties intermediation, seamlessly integrated with existing alS.

\section{FUTURE WORK}

Currently, we are conducting a systematic review of the relevant bibliography, according to the PRISMA methodology (Moher et al., 2009), focused on the identification of other contributions and academic models with scientific validation for the key areas of interest identified in this work.

In the next phase, the work will define functional objectives, as well as the full design of the solution data model, which are both fundamental for the final design of the reference model to be implemented. Finally, our work will implement the functional prototype for further testing and for evaluating results.

\section{REFERENCES}

Chen, G., Xu, B., Lu, M. and Chen, N.-S. (2018). Exploring blockchain technology and its potential applications for education. Smart Learning Environments, 5(1), 1. https://doi.org/10.1186/s40561-017-0050-x

CNOUS. (2017). General specification for the technical implementation. Available at: https://www.google.pt/ url?sa=t\&rct=j\&q=\&esrc=s\&source=web\&cd=\&cad=rja\&uact=8\&ved=2ahUKEwjamebXxr3rAhUIqxoKHT5uDM0QFjAAegQIAxAB \&url=http\%3A\%2F\%2Feuropeanstudentcard.eu\%2Fwp-content\%2Fuploads\%2F2017\%2F02\%2F2017_03_21_Europeanstudent-card-Specifications-v1.pdf\&usg=AOvVaw2TETqkx98Hybiea0vztRX1

Grech, A. and Camilleri, A. F. (2017). Blockchain in Education (EUR - Scientific and Technical Research Reports EUR 28778 EN; p. 136). European Union. http://publications.jrc.ec.europa.eu/repository/handle/JRC108255

Jirgensons, M. and Kapenieks, J. (2018). Blockchain and the Future of Digital Learning Credential Assessment and Management. Journal of Teacher Education for Sustainability, 20(1), 145-156. https://doi.org/10.2478/jtes-2018-0009

Kamišalić, A., Turkanović, M., Mrdović, S. and Heričko, M. (2019). A Preliminary Review of Blockchain-Based Solutions in Higher Education. In L. Uden, D. Liberona, G. Sanchez and S. Rodríguez-González (Eds.), Learning Technology for Education Challenges (Vol. 1011, pp. 114-124). Springer International Publishing. https://doi.org/10.1007/978-3-030-20798-4_11

Lions, T., Courcelas, L. and Timsit, K. (2018). Blockchain for Government and Public Services. European Union Blockchain Observatory \& Forum. Available at: https://www.eublockchainforum.eu/sites/default/files/reports/eu_observatory_ blockchain_in_government_services_v1_2018-12-07.pdf

Moher, D., Liberati, A., Tetzlaff, J. and Altman, D. G. (2009). Preferred Reporting Items for Systematic Reviews and Meta-Analyses: The PRISMA Statement. PLoS Medicine, 6(7), 6. https://doi.org/10.1371/journal.pmed.1000097

Peffers, K., Tuunanen, T., Rothenberger, M. A. and Chatterjee, S. (2007). A Design Science Research Methodology for Information Systems Research. Journal of Management Information Systems, 24(3), 45-77. https://doi.org/10.2753/MIS0742-1222240302

Pelaitis, D. and Spathoulas, G. (2018). Developing a universal, decentralized and immutable Erasmus credit transfer system on blockchain. 2018 Innovations in Intelligent Systems and Applications (INISTA), 1-6. https://doi.org/10.1109/INISTA.2018.8466277

Turcu, C., Turcu, C. and Chiuchisan, I. (2018). Blockchain and its Potential in Education. International Conference on Virtual Learning - ICVL. Available at: https://arxiv.org/abs/1903.09300

Turkanovic, M., Holbl, M., Kosic, K., Hericko, M. and Kamisalic, A. (2018). EduCTX: A Blockchain-Based Higher Education Credit Platform. IEEE Access, 6, 5112-5127. https://doi.org/10.1109/ACCESS.2018.2789929

Williams, P. (2019). Does competency-based education with blockchain signal a new mission for universities? Journal of Higher Education Policy and Management, 41(1), 104-117. https://doi.org/10.1080/1360080X.2018.1520491

Xu, X., Weber, I. and Staples, M. (2019). Blockchain in Software Architecture. In Chapter 5: Blockchain in Software Architecture. In Architecture for Blockchain Applications (pp. 83-92). Springer, Cham. https://doi.org/10.1007/978-3-030-03035-3_5

Xu, X., Weber, I., Staples, M., Zhu, L., Bosch, J., Bass, L., Pautasso, C. and Rimba, P. (2017). A Taxonomy of Blockchain-Based Systems for Architecture Design. 2017 IEEE International Conference on Software Architecture (ICSA), $243-252$. https://doi.org/10.1109/ICSA.2017.33 